Received Date: 28-Sep-2015

Revised Date: 05-Jan-2016

Accepted Date: 11-Jan-2016

\author{
Article Type: Article
}

\title{
Towards a common methodology for developing logistic tree mortality models based on ring-width data
}

Maxime Cailleret $^{1 *}$, Christof Bigler ${ }^{1}$, Harald Bugmann ${ }^{1}$, J. Julio Camarero ${ }^{2}$, Katarina Cufar $^{3}$, Hendrik Davi ${ }^{4}$, Ilona Mészáros ${ }^{5}$, Francesco Minunno ${ }^{6}$, Mikko Peltoniemi ${ }^{7}$, Elisabeth M.R. Robert $^{8,9}$, María Laura Suarez ${ }^{10}$, Roberto Tognetti ${ }^{11}$, Jordi Martínez-Vilalta ${ }^{12,13}$

${ }^{1}$ Forest Ecology, Institute of Terrestrial Ecosystems, Department of Environmental Systems Science, ETH Zürich

${ }^{2}$ Instituto Pirenaico de Ecología (IPE, CSIC), Avda. Montañana 1005, 50059 Zaragoza, Spain

${ }^{3}$ University of Ljubljana, Biotechnical Faculty, Department of Wood Science and Technology

${ }^{4}$ INRA, URFM, Ecologie des Forêts Méditerranéennes, UR 629, Domaine Saint Paul, Site Agroparc, F-84914 Avignon Cedex 9

This article has been accepted for publication and undergone full peer review but has not been through the copyediting, typesetting, pagination and proofreading process, which may lead to differences between this version and the Version of Record. Please cite this article as doi: $10.1890 / 15-1402.1$

This article is protected by copyright. All rights reserved. 
${ }^{5}$ University of Debrecen, Faculty of Science and Technology, Department of Botany, PO Box 14, H-4010 Debrecen, Hungary

${ }^{6}$ Department of Forest Science, University of Helsinki, PO Box 27, Helsinki FI-00014, Finland

${ }^{7}$ Natural Resources Institute Finland (Luke), Jokiniemenkuja 1, 01301, Vantaa

${ }^{8}$ Laboratory of Plant Biology and Nature Management (APNA), Vrije Universiteit Brussel, B1050 Brussels, Belgium

${ }^{9}$ Laboratory of Wood Biology and Xylarium, Royal Museum for Central Africa (RMCA), B3080 Tervuren, Belgium

${ }^{10}$ INIBIOMA, CONICET-Universidad Nacional Comahue, Quintral 1250, Bariloche, Argentina

${ }^{11}$ Dipartimento di Bioscienze e Territorio, Università degli Studi del Molise, Contrada Fonte Lappone, Pesche I-86090, Italy

${ }^{12}$ CREAF, Cerdanyola del Vallès E-08193 (Barcelona), Spain

${ }^{13}$ Univ. Autònoma Barcelona, Cerdanyola del Vallès E-08193 (Barcelona), Spain

*Corresponding author: maxime.cailleret@usys.ethz.ch

\section{Abstract}

Tree mortality is a key process shaping forest dynamics. Thus, there is a growing need for indicators of the likelihood of tree death. During the last decades, an increasing number of treering based studies have aimed to derive growth-mortality functions, mostly using logistic models. The results of these studies, however, are difficult to compare and synthesize due to the diversity of approaches used for the sampling strategy (number and characteristics of 'alive' and 'death' observations), the type of explanatory growth variables included (level, trend, etc.), and the

This article is protected by copyright. All rights reserved. 
length of the time-window (number of years preceding the alive/death observation) that maximized the discrimination ability of each growth variable.

Here, we assess the implications of key methodological decisions when developing tree-ring based growth-mortality relationships using logistic mixed-effects regression models. As examples we use published tree-ring datasets from Abies alba (13 different sites), Nothofagus dombeyi (one site) and Quercus petraea (one site). Our approach is based on a constant sampling size and aims at (1) assessing the dependency of growth-mortality relationships on the statistical sampling scheme used; (2) determining the type of explanatory growth variables that should be considered; and (3) identifying the best length of the time window used to calculate them.

The performance of tree-ring based mortality models was reasonably high for all three species (Area Under the receiving operator characteristics Curve: AUC > 0.7). Growth level variables were the most important predictors of mortality probability for two species (A. alba, N. dombeyi), while growth-trend variables need to be considered for $Q$. petraea. In addition, the length of the time window used to calculate each growth variable was highly uncertain and depended on the sampling scheme, as some growth-mortality relationships varied with tree age.

The present study accounts for the main sampling-related biases to determine reliable speciesspecific growth-mortality relationships. Our results highlight the importance of using a sampling strategy that is consistent with the research question. Moving towards a common methodology for developing reliable growth-mortality relationships is an important step towards improving our understanding of tree mortality across species and its representation in dynamic vegetation models.

\section{Keywords}

Tree mortality, growth, logistic model, mixed-effect, survival, tree-ring, sampling

This article is protected by copyright. All rights reserved. 


\section{Introduction}

Accelerating rates of background tree mortality and related die-off events have recently been reported for many forest ecosystems and have been associated with the progressive increase in temperatures, drought and the duration and frequency of extreme climatic events (e.g., van Mantgem et al. 2009; Allen et al. 2010). As this mortality trend is expected to continue due to global change (Collins et al. 2013), there is a growing demand for early warning signals that allow anticipating where and when forest die-off is likely to occur (cf. Scheffer et al. 2012; Allen et al. 2015). The interest for indicators of tree mortality probability is large in both basic and applied science. First, they can improve our understanding of the causes and mechanisms that lead to tree mortality. Second, predicting which trees or populations are prone to die would help forest managers to design and implement plans to harvest them before their expected death, or to preserve them, for example, by thinning to reduce the intensity of competition for resources such as light or water. Finally, this type of information is key for the development of more robust and reliable Dynamic Vegetation Models whose projections depend critically on how tree mortality is modelled (e.g., Wyckoff and Clark 2002; Friend et al. 2014; Bircher et al. 2015).

Three approaches are commonly used to assess and simulate tree mortality probability. First, the spatio-temporal analysis of mortality patterns from ground surveys or remote sensing can be used to derive empirical relationships between mortality probabilities and indices that reflect environmental conditions such as drought or competition intensity (e.g., Bravo-Oviedo et al. 2006; Clifford et al. 2013; Das et al. 2013; Vilà-Cabrera et al. 2013; Dorman et al. 2015). This method has the advantage of providing large sample sizes and covering large environmental

This article is protected by copyright. All rights reserved. 
gradients. However, the temporal extent is limited (<50 years), and this phenomenological approach provides few insights into the mechanisms underlying the mortality process itself. Second, physiological indicators such as changes in the plant hydraulic system (reduced water transport capacity due to xylem embolism, potentially causing hydraulic failure) or the carbon budget (decrease of non-structural carbohydrate concentrations potentially leading to 'carbon starvation') can be used to reveal a decrease in tree vitality and hence an increase in the likelihood of mortality (McDowell et al. 2013; Tague et al. 2013). Although this mechanistic approach is highly promising, the development of such indicators requires intensive, long-term tree monitoring involving measurements of the pools and fluxes of carbon and water at high temporal and structural resolution (i.e., in different organs), and even in this case the predictive ability of current mortality models is limited (McDowell et al. 2013). Moreover, this type of monitoring is very costly and can be implemented for a few trees at highly instrumented research sites only, thus making results for a broad suite of species rather unlikely. Third, focusing on tree radial growth is a promising alternative as it (i) can be investigated easily for many individuals; (ii) has the advantage of covering long time periods, thus including the potential of considering lagged mortality (e.g., Bigler et al. 2007; Camarero et al. 2015); and (iii) is highly appropriate to reflect the spatio-temporal variability of environmental conditions and tree vitality (Dobbertin 2005). Indeed, cell growth and formation are among the first processes impacted by environmental stress (low temperature or decline in turgor due to drought; Palacio et al. 2014; Lempereur et al. 2015), are highly sensitive to crown defoliation (Puri et al. 2015), and may be associated with non-structural carbohydrates reserves (Heres et al. 2014, but see Palacio et al. 2014). Radial growth data also show high potential to predict individual mortality from tree rings (e.g., Bigler and Bugmann 2004) or forest inventory data (e.g., Holzwarth et al. 2013). Forest inventories usually cover a wide range of tree species and large areas, but they almost always

This article is protected by copyright. All rights reserved. 
lack an annual resolution, whereas tree-ring data are available from a very large number of studies, each of which typically covers one to a few species growing at one to a few sites (e.g., Gillner et al. 2013, but see Kane and Kolb 2014).

During the last 15 years, an increasing number of tree-ring based studies aimed at deriving growth-mortality functions (Table A1). Most of them applied logistic regression models; however, they did not pay attention to several methodological issues that affect the structure and performance of such models:

(1) The number of trees and the ratio between 'alive' and 'death' observations used to calibrate the model are usually chosen arbitrarily despite having a strong impact on model fit (Hartmann et al. 2007).

(2) A range of statistical schemes may be employed to sample alive and death observations within a stand or even within a single tree, from the inclusion of all available observations (i.e., longitudinal data) to a specific focus on the years during which mortality occurred (i.e., crosssectional data).

(3) The type and combination of explanatory growth variables used may matter as well. They can be calculated using ring-width $(R W)$ or basal area increment $(B A I)$ data, the latter depending less on tree diameter and being more closely related to biomass increment (Bowman et al. 2013). Growth level variables, i.e. averages of $R W$ or $B A I$ over certain time windows, are commonly used, as prolonged periods of low radial growth tend to be associated with an increased tree mortality probability (Pedersen 1998, Wyckoff and Clark 2000, Bigler and Bugmann 2004). However, as some slow-growing trees may survive for very long periods (e.g., old Pinus longaeva; Schulman 1958) and some fast-growing trees have been observed to die after a rapid growth decrease, models may also include growth trend variables that reflect the rate of change

This article is protected by copyright. All rights reserved. 
in mean growth within a given time period (see Bigler and Bugmann 2004). Similarly, as mortality probability is highly related with tree size (Das et al. 2007; Holzwarth et al. 2013), relative growth variables may be used to consider that small trees are relatively more productive than large ones given a similar diameter increment, or tree diameter (size) may be used directly. Other growth variables have been used as well, such as the inter-annual variability of growth, which was positively related with mortality probability in several studies (e.g., Suarez et al. 2004; Macalady and Bugmann 2014), or the temporal autocorrelation in the ring-width series (Camarero et al. 2015).

(4) The length of the time window (number of years preceding the alive/death observation) used to calculate each growth variable differs strongly among studies. Although several authors tested different time windows, no common methodology exists to select the best one, and thus time windows were selected somewhat arbitrarily in previous studies (see Table A1).

All these factors make the comparison of results among mortality studies and subsequent biological interpretations difficult, and hinder the feasibility of robust meta-analyses that would be highly useful to detect differences in tree growth patterns prior to mortality among sites, among species, and between the different factors triggering tree death.

In this paper, we use data from published mortality studies using tree rings and systematically compare different methodologies for developing and assessing growth-mortality relationships. We aim to provide specific recommendations on good practices to predict tree mortality from radial growth data, depending on the objectives of the study and data availability. Specifically, we address the following questions, all of which affect the predictive capacity of the resulting statistical models:

(1) What scheme should be used to sample alive and death observations?

This article is protected by copyright. All rights reserved. 
(2) What type of explanatory growth variables should be considered, and which specific metrics should be used?

(3) How can the best length of the time window be determined to calculate the growth variables?

(4) How should the best multi-variable logistic model be built, considering the collinearity between growth variables, and how can the impact of each of them on predicted mortality probability be best quantified?

\section{Materials and Methods}

\section{TREE-RING DATASETS}

We re-analysed tree-ring datasets covering three species and several sites. In all cases, living and dead trees were sampled at the same sites. Each species dataset differed in terms of the (i) number of sites considered; (ii) number of trees sampled; (iii) ratio between living and dead trees; and (iv) distribution of the death events over time (Table 1). These datasets cover ecologically contrasting species including Abies alba Mill., Nothofagus dombeyi (Mirb.) Oerst., and Quercus petraea (Matt.) Liebl., which were selected to reflect the diversity of sampling strategies observed in the literature (Appendix B).

Abies alba is a gymnosperm from European temperate mountain forests. Tree-ring data were taken from the studies of Bigler et al. (2004), Cailleret et al. (2014), Linares and Camarero (2012) and Lombardi et al. (2008). This dataset includes 195 dead and 321 living trees from 13 different sites with a wide range of DBH (diameter at breast height) and cambial age. Trees died between 1955 and 2008.

This article is protected by copyright. All rights reserved. 
Nothofagus dombeyi is an evergreen angiosperm from South America with diffuse-porous wood. The trees were cored and ring widths measured by Suarez et al. (2004). The sampling size is relatively low, as only 43 dead and living trees growing at one site were analyzed, but the variability in tree size and age was high; trees died in a single event in 1998.

Finally, Quercus petraea is a deciduous angiosperm with ring-porous wood, dominant in dry European temperate forests. Tree-ring data were available from one site (I. Mészáros; unpublished data). In this case, the number of dead trees sampled is low compared to the living ones (25 dead and 194 living trees), and their DBH was not measured. Mortality occurred over a relatively long period, extending from 1953 to 2000.

At every site, tree-ring widths had been measured to the nearest $0.01 \mathrm{~mm}$ on increment cores taken at breast height $(1.3 \mathrm{~m})$. When a core did not reach the pith, the total missing width and the number of missing rings were estimated by interpolating the distance to the pith using the curvature of the innermost rings of the sample, which allowed us to estimate tree cambial age (at breast height). DBH data were available for two species only (A. alba and N. dombeyi). Annual DBH values were reconstructed for these species by subtracting DBH measured at the time of coring by the ring width produced earlier ('from outside to inside'; annual DBH values were rescaled in case of negative $\mathrm{DBH}$ calculated at age $=1$ ).

\section{MODELLING APPROACH}

Generalized linear models with binomial error distribution (i.e. logistic regression) were used to predict the survival probability of a tree $i$ at time $t$, hereafter labelled $\operatorname{Pr}\left(Y_{i, t}=1\right)$, and to analyse the corresponding growth-mortality relationships (Bigler and Bugmann 2004). Logistic

This article is protected by copyright. All rights reserved. 
regression models with fixed effects were used for $N$. dombeyi, as trees were growing at one site and died on the same date (Eq. 1):

$\log \left[\frac{\operatorname{Pr}\left(Y_{i, t}=1\right)}{\left(1-\operatorname{Pr}\left(Y_{i, t}=1\right)\right)}\right]=\alpha_{0}+\beta_{0} * G_{i, t, p}$

where $\operatorname{Pr}\left(Y_{i, t}\right)$ follows a binomial distribution with $Y_{i, t}=0$ indicating that tree $i$ is dead at time $t$, while $Y_{i, t}=1$ indicates that the tree is alive; $\alpha_{0}$ is the intercept; and $\beta_{0}$ is the coefficient for the growth variable calculated over a time window of length $p\left(G_{i, t, p} ; p\right.$ for period $)$.

When the tree-ring dataset included multiple sites and/or the mortality events occurred during several years (i.e., A. alba and Q. petraea), logistic regression models with mixed effects were used. The species-specific growth-mortality relationship was provided by the fixed effects of the model. To consider that growth-mortality relationships may change among sites due to the different relative contributions of environmental stress and biotic attacks, random effects were estimated for the growth variable (i.e., the slope), with study site as the grouping variable. In order to remove the potential impact of annual disturbances that can modify tree survival at a given site irrespective of growth (e.g., windthrow), random effects were also estimated for the intercept in groups of years nested in each study site (Eq. 2):

$\log \left[\frac{\operatorname{Pr}\left(Y_{i, t}=1\right)}{\left(1-\operatorname{Pr}\left(Y_{i, t}=1\right)\right)}\right]=\alpha_{0}+\alpha_{s t}+\left(\beta_{0}+\beta_{s}\right) * G_{i, t, p}$

where $\alpha_{s t}$, and $\beta_{s}$ are vectors of random effects, with $\alpha_{s t} \sim \mathrm{N}\left(0, \sigma^{2}{ }_{s t}\right)$ being the random effect for the intercept grouped by year $(t)$ nested in each study site $(s)$, and $\beta_{s} \sim \mathrm{N}\left(0, \sigma^{2} \beta_{s}\right)$ the random effect for the growth variable grouped by study site (random effect of the slope).

This article is protected by copyright. All rights reserved. 
Both fixed-effects (Eq. 1) and mixed-effects (Eq. 2) models were designed for one single growth variable as detailed above, but they were also used with a combination of up to $X$ growth variables. Thus, the mixed-effects model was structured as follows (Eq. 3):

$\log \left[\frac{\operatorname{Pr}\left(Y_{i, t}=1\right)}{\left(1-\operatorname{Pr}\left(Y_{i, t}=1\right)\right)}\right]=\alpha_{0}+\alpha_{s t}+\sum_{x=1}^{x=X}\left(\beta_{0 x}+\beta_{s x}\right) * G x_{i, t, p x}$

where $\beta_{0 x}$ are the coefficients for each growth variable calculated over a time window $p x\left(G x_{i, t, p x}\right)$, and $\beta_{s x}$ are the vectors of random effects for each growth variable grouped by study site, with $\beta_{s x}$ $\sim \mathrm{N}\left(0, \sigma^{2} \beta_{s x}\right)$.

\section{STATISTICAL SAMPLING SCHEMES USED FOR MODEL CALIBRATION}

We tested different approaches for sampling the 'alive' observations, depending on the research questions being addressed. Note that the ratio between death and alive observations that were derived from these samplings is not representative of stand-scale mortality rates observed in the field. Evidently, this precludes the use of these logistic models to predict mortality at the population level, which was not intended here.

\section{All years are considered}

We first used a sampling strategy that considers all the years of each tree's life as recorded in the tree-ring data (sampling $T$ for Total number of years; Fig. C1). Here, the random effect for the intercept grouped by year was not considered in the logistic model (vector $\alpha_{s t}$ of equations 2 and 3). This sampling is preferable if one wants to (1) better understand the growth patterns prior to the mortality of a specific tree in a specific year, (2) derive growth-mortality relationships that are

This article is protected by copyright. All rights reserved. 
reliable for all types of mortality and all tree developmental stages, or (3) use these relationships to simulate individual-tree mortality in Dynamic Vegetation Models (Bircher et al. 2015).

\section{Focus on the years for which mortality occurs}

To predict which tree will die during a specific mortality event (e.g., drought-induced mortality in a certain period), and to compare the growth patterns of the living trees and now-dead trees prior to this event, we sampled only the death/alive observations - and the associated growth variables - corresponding to the years when mortality occurred. We thus generated unequal samplings $(U)$ in which all the 'alive' observations of a given year were used (Fig. C1), which usually leads to a lower ratio of alive/death observations than sampling $T$.

To build models that are able to predict well both survival and mortality, rather than only survival, the prevalence of the 'alive' observations in the data has to be reduced (see Lawson et al. 2014). Thus, as a third approach a paired sampling $(P)$ was generated; i.e. for each dead tree that died at time $t$, we sampled only one 'alive' observation from the same site at the same $t$ (Fig. C1). The pair was removed from the data set if one of the two trees did not contain a given explanatory variable. The 'alive' observation was sampled from both living and now-dead trees and chosen either randomly $(P-R$; with replacement) or from a tree that was as similar as possible to the dead tree in terms of cambial age ( $P$ - $A$; note that an 'alive' observation could be used repeatedly if the number of death events was higher than the number of survival events). The $P-A$ approach is often employed in studies to help control for the temporal changes in microenvironmental conditions.

We also assessed if the structure and performance of the mortality models was impacted by (i) the status of the trees used to sample the 'alive' observations (e.g., living trees only vs. dead trees only; Appendix C), (ii) sample size (Appendix D), and (iii) the random selection of the 'alive' 
observations (Appendix E). For Nothofagus dombeyii, all the trees died at the same date (last ring formed in 1997). As a consequence, 'alive' observations arise from living trees only, and the determination of the pairs (randomly or per age) was not relevant. Moreover, as the number of dead trees was equal to the number of living ones, unequal sampling could not be drawn, which restricted us to study the sampling schemes $P-A$ and $T$.

\section{ASSESSMENT OF MODEL PERFORMANCE}

Model-predicted survival probabilities $\left(p r_{i, t}\right)$ were compared with the individual binary alive/death information from the observed data set to assess model performance.

Although calibration metrics such as the Akaike Information Criterion (AIC) are commonly used (Appendix A), AIC is strongly positively correlated with the number of samples used to calibrate the model, and depends on the equitability of the sampling (i.e., prevalence of the living observations; see Lawson et al. 2014; Appendix F). This is highly problematic when comparing the performance of models fitted to different sample sizes and properties. Using a "minimum AIC approach" would lead to a preferential selection of models with low sample size, i.e., models for which the growth variables are calculated using a large time window (Appendix F).

Discrimination metrics are more suitable for our purpose as they reflect the ability to separate survival $\left(\mathrm{Y}_{\mathrm{i}, \mathrm{t}}=1\right)$ and death $\left(\mathrm{Y}_{\mathrm{i}, \mathrm{t}}=0\right)$ observations based on $p r_{i, t}$ (Lawson et al. 2014). Binary metrics such as sensitivity (fraction of true positive cases, i.e., the tree survived and the model predicts a survival event) or specificity (fraction of true negative cases, i.e., the tree died and the model predicts a death event) can be used, but they require determining a threshold that would classify a tree as dead or alive, whose value strongly depends on the rather arbitrary method used for its calculation (cf. Bircher et al. 2015).

This article is protected by copyright. All rights reserved. 
As an alternative, continuous discrimination metrics such as the Area Under the Receiver Operating Characteristic (ROC) Curve (AUC) are preferable, especially due to their independence of the equitability of the sampling. A ROC curve is constructed by plotting the ratio of true positives to false positives $(1$ - specificity) for all possible threshold values of the estimated survival probability (Fielding and Bell 1997). AUC values range from 0 to 1 , with 0.5 indicating a random model. A model providing an excellent prediction has AUC $\geq 0.9$, a fair model $0.7 \leq$ AUC $<0.9$ (Swets 1988), and AUC $<0.7$ indicates a poor model.

All mixed-effects models were fitted using the package lme4 of the software R ( R Development Core Team; Bates et al. 2015), and their AUC was calculated using the package ROCR (Sing et al. 2013). In the case of very large eigenvalues and a perfect model $(A U C=1)$, the significance of the effect of each growth variable was assessed using Markov Chain Monte Carlo techniques (package MCMCglmm; Hadfield 2010), and Firth's penalized-likelihood logistic regression (package logistf; Heinze et al. 2013), respectively.

\section{GROWTH VARIABLES}

Trees can die during the growing season when ring formation is not finished, which induces an incomplete outermost ring. As the precise (intra-annual) timing of tree death was not available, we did not consider the last ring of the dead trees to avoid a bias in performance of the models that use recent growth to discriminate dead from living trees. Thus, the year of death considered here was a proxy and was defined as the year prior to the formation of the outermost ring. Basal area increments $(\mathrm{BAI})$ were calculated from ring-width $(\mathrm{RW})$ data for all trees whose $\mathrm{DBH}$ information was available (i.e., all trees except for dead $Q$. petraea), and both variables were used to reflect different growth characteristics of tree $i$ at time $t$ (Fig. 1).

This article is protected by copyright. All rights reserved. 
Absolute and relative growth level

Growth level variables were defined as the average growth of the last (outermost) $p$ rings (years) (Eq. 4):

$$
R W_{i, t, p}=\operatorname{mean}\left(\sum_{y=t}^{y=t-p+1} R W_{i, y}\right)
$$

$R W_{i, t, p}$ corresponds to the width of the last ring when $p=1$. The same equation was used to calculate, and the relative growth variable $\operatorname{relBAI}_{i, t, p}$ was calculated as the ratio of $B A I_{i, t, p}$ and $B A_{i, t}$. We also tested the impact of the log-transformation of these growth level variables on model performance, since logarithms are frequently used to the reduce the effect of high growth values on $\operatorname{Pr}\left(Y_{i, t}=1\right)$ (see Appendix A).

\section{Growth trend}

The slopes of local linear regressions fitted over the last $p$ years were used to characterize growth trends with $R W\left(s l o R W_{i, t, p}\right)$ and $B A I\left(s l o B A I_{i, t, p}\right)$, and were used as independent variables in the growth-mortality models (Fig. 1).

\section{Growth variance and autocorrelation of annual ring-widths}

The mean sensitivity $(M S)$ of the raw data or of the detrended chronology is often used to assess the inter-annual variation in the ring-width chronology. However, $M S$ is strongly correlated with the Lag1-autocorrelation of the rings (A1; see Bunn et al. 2013) and is not necessarily a good proxy of growth variance. Thus, after detrending each series using a power transformation (see Cook and Peters 1987), we estimated both variance and autocorrelation in tree-ring growth using the standard deviation and the AR1 coefficient of an autoregressive model fitted to each detrended chronology (Bunn et al. 2013; Appendix G). 


\section{DETERMINATION OF THE BEST-FITTING TIME WINDOW FOR CALCULATING}

\section{GROWTH VARIABLES}

The next step for deriving reliable logistic mortality models was to define the number of rings $(p)$ that should be considered to calculate the growth variables. All growth variables were calculated using $p$ rings that ranged between $p_{\min }$ and $p_{\max }$, with $p_{\min }=1$ for growth level variables, $p_{\min }=2$ for growth trend variables, and $p_{\min }=10$ for the growth variance and autocorrelation variables. $p_{\max }$ was set to 50 rings so as to consider potential long-term negative effects of intense stress and disturbances on tree status.

Logistic models with a single growth variable (Eqs. 1 and 2)

In the classical approach, all trees were used to calibrate the logistic models, using every combination of $p$ and growth variables. However, with the increase of $p$, young trees (or trees for which partial tree-ring data were available) were increasingly excluded from the calibration dataset, inducing a decrease of sample size (Fig. 2). The change of AUC with changing $p$ may thus be biased due to differences in the set of trees that were selected in the sample (number and characteristics of the trees). Therefore, we assessed the change of model AUC with $p$ for identical samplings using an iterative process, hereafter called constant sampling approach. We firstly used the trees with at least $p_{\max }$ rings and calculated model AUC obtained for every $p$ with this dataset. Then, we used the same approach with the trees with at least $p_{\max }-1$ rings (same or higher number of trees than previously), etc., down to $p_{\min }$. We ended up with $\left(p_{\max }-p_{\min }\right)$ different patterns of changes in model AUC over $p$ (Fig. 2), where AUC at each $p$ was calculated from the same sample of trees. For each of these 'curves', the $p$ that maximized model AUC was recorded. Finally, from the set of all these 'curves', we determined the proportion of samples whose AUC 
was maximized at each $p$. The $p$ with the highest proportion of samples was then considered as the best-fitting time window (hereafter called best-fitting $p$ ). As only one sample was available at $p_{\text {max }}$, we defined that the best-fitting $p$ was equal to $p_{\max }$ only when model AUC increased monotonically with $p$.

\section{Logistic models with multiple growth variables (Eq. 3)}

Under the constant sampling approach, there are $\left(p_{\max }-p_{\min }\right)^{x}$ combinations of models that include $X$ growth variables that can be calculated using $p_{\min }$ to $p_{\max }$ different time windows. This results in $>6^{\prime} 000^{\prime} 000\left(=50^{4}\right)$ models that have to be fitted to assess the best-fitting time window of 4 variables with $p_{\min }=1$ and $p_{\max }=50$. In order to reduce simulation time, we (i) used Differential-Evolution optimization algorithms (R package DEoptim; Mullen et al. 2011) to detect the combination of best-fitting $p$ that optimizes model AUC while escaping local minima (Storn and Price 1997), (ii) developed one logistic model including all RW-related growth variables $(R W$, sloRW, $S D, A 1)$, and (iii) used three possible $p_{\max }(20 ; 35 ; 50)$ that would allow us to disentangle the effects of changing calibration dataset and changing the maximum length of the time windows. To assess the relative importance of each growth variable on predicted $p r_{i, t}$, we calculated the proportion of the total variance in $p r_{i, t}$ explained by the variation in each explanatory variable (i.e., effect size of the fixed effects) using variance analysis techniques.

This article is protected by copyright. All rights reserved. 


\section{Results}

\section{DIFFERENCES IN BEST-FITTING P AMONG APPROACHES}

Two main patterns were obtained when comparing the best-fitting $p$ determined using the classical and the constant sampling approaches. On the one hand, in some cases the best-fitting $p$ was consistent in both approaches, e.g., when using growth level variables for A. alba, and on the paired sampling schemes for Q. petraea (Figs. 2 and 3; Appendix H). For instance, on samplings $P$-A for $A$. alba and $Q$. petraea, the maximum AUC of models using $R W_{i, t, p}$ was obtained at $p=2$ and $\mathrm{p}=1$, respectively, irrespective of the approach. By contrast, with $s l o R W_{i, t, 50}$ for $A$. alba $(P$ A), all samples for which the logistic model could be calibrated showed the highest performance at $p=50$ (Fig. 2). Admittedly, this was based on a single sample, but it was coherent with the increase in model performance over $p$ observed for all other samples and also when using the classical approach.

On the other hand, the determination of the best-fitting $p$ on the sampling scheme $P-A$ of $N$. dombeyi led to different results (Figs. 2 and 3; Appendix H). For $R W_{i, t, p}$, the classical approach revealed a lower AUC of models that used $p<30$ rings, with an optimal AUC at $p=31$. This pattern was not found when analysing the change in AUC over $p$ for samples with constant size, in which maximum AUC occurred at $p=6$ and $p=17$ for $27 \%$ and $56 \%$ of these samples, respectively (Fig. 2). Samples that included only trees $>30$ years old showed much higher AUC at $p<30$ than samples with both old and young trees. For instance, at $p=17$, AUC ranged between 0.65 and 0.80 depending on the sampling that was applied (Table 2). The reduction in AUC towards lower $p$ that was observed with the classical approach for $N$. dombeyi $(P-A)$ was caused by a strong increase in the number of young trees in the sample for which the relationship

This article is protected by copyright. All rights reserved. 
between $R W_{i, t, p}$ and tree status was not significant while it was significant for older trees (divergence in the late 1960's; Figs. 2 and 4). This was not observed for A. alba and Q. petraea for which the relationships between $R W_{i, t, p}$ and tree status were similar among tree size classes and the reduction in the number of pairs was not as pronounced (i.e., 95\% of $A$. alba trees were older than 50 years; Fig. 2).

\section{DIFFERENCES AMONG STATISTICAL SAMPLING SCHEMES}

Within a species and for a given growth variable, the determination of best-fitting $p$ depended also strongly on the statistical sampling schemes used to calibrate the models. For A. alba, the best-fitting $p$ for calculating slo $R W_{i, t, p}$ ranged between 27 and 33 years for the samplings $P-R$ and $U$, but was 50 years for the samplings $P-A$ and $T$ (Table 2). This instability in the determination of the best-fitting $p$ was also observed depending on whether 'alive' observations were selected from living trees or dead trees only (Appendix C), and within statistical sampling schemes, especially when sample size was limited (e.g. < 40 pairs; Appendices $\mathrm{C}$ and D). In addition, model performance also varied among statistical sampling schemes (Table 2, Appendix C). Model AUC obtained from unpaired samplings was higher than AUC obtained from paired samplings. For instance, models that related $B A I_{i, t, 1}$ with survival probability of $A$. alba showed an AUC of 0.83 and 0.71 for the $U$ and $P$-A samplings, respectively (Table 2). This result simply reflects that alive observations are more easily predicted than death observations, and thus should not be interpreted as unpaired samplings being superior for predicting mortality.

This article is protected by copyright. All rights reserved. 


\section{DIFFERENCES AMONG GROWTH VARIABLES IN UNIVARIATE MODELS}

For the growth level variables, there was no evidence of higher prediction accuracy of survival probability by $B A I$ than by $R W$. For both variables the best fits were typically obtained using the last year or the last two years for $A$. alba (Fig. 3; Table 2). Using the $P$ - $A$ sampling scheme for $N$. dombeyi, the best-fitting $p$ changed depending whether the model used $R W_{i, t, p}$ or $B A I_{i, t, p}$ as explanatory variable (17 and 5 years, respectively; Table 2). However, this difference was not robust because of the high uncertainty in best-fitting $p$, and as AUC values obtained at $p=5$ for $R W_{i, t, p}$ were almost identical to those at $p=17$ (Fig. 2 and Table 2). Similarly, the log transformation of the growth level variables did not significantly improve model AUC (Appendix I). The use of relative growth level variables instead of absolute ones slightly decreased model AUC on average (-0.05 to +0.06 between models that used BAI and relBAI; Table 2), except for the samplings $T$, which strongly benefitted from this change $(+0.04$ to +0.12$)$.

The temporal trend in RW series was not a suitable predictor of survival probability $(\mathrm{AUC}<0.7)$, except for the samplings $U$ and $T$ for $A$. alba and $N$. dombeyi. For the other samplings, $B A I$ should be preferred for fitting linear regressions (i.e., sloBAI). Between 25 and 30 years should be considered to calculate growth trend variables of $Q$. petraea. No unique best-fitting $p$ emerged for N. dombeyi, whereas for A. alba it was $>25$ years (cf., Fig. 3).

For the sampling schemes $P$ and $T$, logistic models that used $S D$ or $A l$ did not predict survival probability correctly. However, although the averaged relationships between these growth variables and survival probability were not significant for unpaired samples, the models' AUC were $>0.7$, revealing that the sign and magnitude of these relationships changed among sites (Table 2). Despite the large uncertainty in best-fitting $p$, usually short time windows (<20 years) were obtained.

This article is protected by copyright. All rights reserved. 


\section{BEST MULTIVARIATE MODELS - SIGN OF THE GROWTH-MORTALITY RELATIONSHIPS}

We derived multivariate models to determine to what extent multivariate models perform better than univariate ones. Moreover, as most growth variables were correlated (Appendix J), they were helpful to assess and rank the true effect of each of them, i.e., to assess the sign of the growth-mortality-relationships and the contribution of each growth variable to the modelpredicted survival probability.

Similarly to models with one single growth variable, the structure and performance of the best multivariate models changed as the maximum length of the time window $\left(p_{\max }\right)$ considered to calculate the growth variable increased, and with the statistical sampling scheme (Table 3 ). For $A$. alba, AUC was lower for paired than for unequal samplings, while this was not clear for $Q$. petraea, probably because of the low sample size. For paired samplings, mortality models that included four growth variables showed higher AUC than the best univariate models $(+0.06,+0.09$ and +0.11 , for $A$. alba, Q. petraea, and $N$. dombeyi, respectively). On average, this increase in AUC was lower in the case of samplings $\mathrm{U}$ and $\mathrm{T}(+0.02,+0.03$ and +0.05$)$.

As expected, survival probability was positively correlated with growth level and growth trend variables, the former being predominant for predicting survival probability of A. alba while the pattern was reversed for $Q$. petraea (Appendix K). When the relationship was significant, growth level variables of $A$. alba were mainly calculated with $p$ ranging from 1 to 3 years for $R W_{i, t, n}$ (Tables 3 and B3). This best-fitting $p$ was much more variable for growth trend variables (from 3 to 31 years), although it was mostly between 25 and 34 years for $Q$. petraea (Table 3 ).

This article is protected by copyright. All rights reserved. 
The relationships with $S D$ and $A l$ were slightly significant and were only reported for specific combinations of species, $p_{\max }$ and sampling scheme. For instance, $S D$ was never related to survival probability of $Q$. petraea and $N$. dombeyi, and only 5 of the 12 samples of $A$. alba showed a negative relationship, with the time window used to assess $S D$ being rather uncertain. Results were even less clear for A1. For A. alba and N. dombeyi, the sign of the relationship between $A l$ and survival changed with $p_{\max }$ and among sampling schemes (Table 3 ), and was mainly negative when alive observations could arise from dead trees (Appendix C).

\section{Discussion}

\section{POTENTIAL AND LIMITATIONS OF TREE RING-WIDTHS AS PREDICTORS OF TREE}

\section{DEATH}

As revealed by the high AUC values of the multivariate models, there is a high potential of using tree-rings as a robust indicator of tree mortality probability (Bigler and Bugmann 2004). In the present study, AUC was calculated using the same data as for model calibration and optimized using appropriate algorithms. As our aim was to assess growth-mortality relationships per se, and not to predict mortality probability by applying the models, they were not validated on an independent dataset (such as in Bigler and Bugmann 2004), and thus their performance may be exaggerated. Nevertheless, AUC can be quite low, e.g., for $Q$. petraea, because growth may not reflect all environmental influences that drive mortality probability (Das et al. 2008; Kane and Kolb 2010; Ferrenberg et al. 2014), and because the date of tree death estimated using ring observations on cores may be biased due to partial cambial dieback (Bigler and Rigling 2013).

This article is protected by copyright. All rights reserved. 
If prediction is the goal, the performance of tree-ring based mortality models may be improved by standardizing the growth estimates for each site, e.g. using the "Regional Curve Standardization" method (Esper et al. 2003). As the species-specific effect of growth on mortality may depend on the local conditions of the study site, as revealed by some significant random effects for $A$. alba, these relative growth values are probably better indicators of the vitality of a single tree within a specific site (see Das and Stephenson 2015), and are of higher interest to forest managers (e.g., the mortality probability is higher than $50 \%$ if the last ring-width was below a given percentage of mean growth). However, model calibration and conclusions become more vulnerable to the sampling strategy. When the data are not representative, i.e., not all trees are sampled, or the sampled plots do not fully portend actual forest dynamics, it may be difficult to use growth variables that are expressed relative to those of other trees.

Another way to improve the statistical determination of growth patterns prior to mortality would be to use a different statistical modelling approach (e.g., Wyckoff and Clark 2000). In the present study, we assumed that the response variable, (i.e., tree status) follows a binomial distribution, but a Weibull distribution could also be used (Wyckoff and Clark 2002). Other methods may also be powerful, such as the quickest detection method (Carpenter et al. 2014), autologistic models, neural networks (Hasenauer et al. 2001), multivariate adaptive regression splines, classification and regression trees or general additive models (Austin 2007).

\section{DATA REQUIREMENTS: SAMPLE SIZE AND STATISTICAL SAMPLING SCHEMES}

Tree-ring based analyses are strongly influenced by sampling schemes.

First, the number of sampled trees affects growth-mortality relationships, analogously to the quantification of climate-growth associations (Mérian et al. 2013). A large instability in the best-

This article is protected by copyright. All rights reserved. 
fitting $p$ of the different growth variables was observed among and within the different statistical schemes for $Q$. petraea (Appendix E) and within samplings of $A$. alba with 40 pairs $(P-R$; Appendix D), revealing that a small sampling size may bias the structure and performance of the best mortality models.

Second, growth-mortality relationships depend on the characteristics of the sampled trees, including their age, size and social status (cf. Martín-Benito et al. 2008 for climate-growth associations), independently of the total number of samples. The sampling design (e.g., random or stratified selection of the trees) can bias the determination of the best mortality models, similarly to tree-ring based metrics of stand-scale forest productivity (Nehrbass-Ahles et al. 2014).

Third, as revealed by the significant random effect of the site on the growth variables of singleand multi-variable logistic models of $A$. alba, growth-mortality relationships are most likely not only species-specific, but depend on the combination site $x$ species $x$ mortality driver (Wunder et al. 2008; Macalady and Bugmann 2014; Camarero et al. 2015).

In consequence, in order to assess reliable growth-mortality relationships for a given species, we recommend (1) to study multiple sites in contrasting environmental conditions, either to calibrate the model and/or to validate it (e.g., Bigler and Bugmann 2004); and (2) to choose the field and statistical sampling design based on the research questions (see Materials and Methods; Hartmann et al. 2007).

The coring of trees, measuring ring-widths and cross-dating each individual growth series is quite time-consuming, and therefore the number of samples is always limited. The present study highlights the necessity and utility of assessing the uncertainty in the structure and performance of the best mortality models using re-sampling techniques (e.g., for Q. petraea; see Appendix E) 
or employing different statistical sampling designs. The latter option may also reveal effects that were not accounted for in the initial model structure. For instance, comparing the performance of models calibrated with $P-A$ and $P-R$ samplings may indicate any effect of tree size/age, and/or a temporal shift in growth mortality relationships (e.g. for $N$. dombeyi), while sampling the alive observations from dead trees only or from living ones can reveal specific properties of the treering series of dead trees (Appendix C). Site-specific effects of growth variables can be accommodated using hierarchical models with random site effects of the intercept and the slopes, as illustrated in our models for A. alba (cf. Eq. 2).

\section{DETERMINATION OF THE BEST-FITTING TIME WINDOW}

Instead of arbitrarily selecting and comparing different time windows $(p)$, we tested all possible $p$ between $1\left(p_{\min }\right)$ and $50\left(p_{\max }\right)$ years using an objective statistical approach that optimized the discriminatory power of each explanatory variable. This procedure allowed for considering longterm changes in growth dynamics and detecting local maxima in model performance. However, with the increase in $p_{\max }$, young trees (or trees whose innermost rings are lacking) were progressively excluded from the calibration dataset. This may induce a change in the structure and performance of the best model if trees of different ages have different growth-mortality relationships and when sample size is low (e.g., for $N$. dombeyi). To account for both the effect of increasing $p_{\max }$ and the change of the calibration dataset, we suggest that one should follow the constant sampling approach, which may highlight potential developmental shifts in speciesspecific growth-mortality relationships. Such a shift can occur gradually as the main drivers of tree mortality usually change as trees grow and their micro-environment changes (e.g., Das et al. 2007). Trees mostly suffer from excessive shading during the suppressed juvenile stage, but with

This article is protected by copyright. All rights reserved. 
increasing size, they become less shade-tolerant and less able to survive at low growth rates (Valladares and Niinemets 2008). Tall trees may also be more prone to drought-induced mortality than small ones (Bennett et al. 2015) due to lower whole-tree hydraulic conductance (hydraulic limitation hypothesis; Ryan et al. 2006). The change in growth-mortality relationship may be sudden as a result of an extreme climatic event or due to the abrupt emergence of pathogens or insect outbreaks in the study area. In the case of insect-related mortality events, we expect partial decoupling between growth and mortality processes, as mortality probability would be more related to defence characteristics (e.g., density of resin ducts against bark beetle attacks) than to radial growth per se (Ferrenberg et al. 2014).

\section{GROWTH VARIABLES}

In the present paper, we deliberately did not test all the growth variables used in earlier studies but selected the most common ones or those that had shown a strong relationship with mortality probability in previous studies (Bigler and Bugmann 2004; Kane and Kolb 2014; Macalady and Bugmann 2014). In the case of low performance of univariate models (AUC < 0.7; e.g., based on paired samplings for $Q$. petraea and $N$. dombeyi), mortality models that included four growth variables performed better than the best univariate ones (increase in AUC > 0.1) due to the additional information provided by each variable. Variance decomposition analyses performed on multivariate models highlighted that growth level variables were a better indicator of tree survival probability in two of the three species (A. alba and N. dombeyi), while growth-trend variables should be considered in the case of $Q$. petraea. No specific recommendation can be made regarding the time windows that should be used to calculate growth level and growth trend variables as they varied among the three species and among the sampling schemes.

This article is protected by copyright. All rights reserved. 
$B A I$ is often considered to be a biologically more meaningful growth level variable than $R W$, as it depends less on tree size and approximates biomass increase better (Bowman et al. 2013). This may be an important issue when the trees have different DBH or age, such as in $P-R$ and $U$ sampling schemes. However, and similar to Macalady and Bugmann (2014), in our case BAI did not perform better than $R W$ in segregating living and dead trees. The reverse pattern was even found for the sampling $T$, in which all available rings were used. As $B A I$ is very low during the juvenile phase compared to $R W$ (e.g., first 20 years; Fig. 1 and 4), models using $B A I$ tend to overestimate the death probability of young trees. In this case, relative growth level variables such as relBAI should be preferred (Das et al. 2007; Holzwarth et al. 2013).

Using $R W$ or $B A I$ data also mattered for calculating growth trend variables. When linear regressions were fitted to $R W$ series, the differences in the growth trend prior to the alive vs. death observations could be missed (or underestimated). Living trees usually have higher growth rates than dying trees, and therefore their radial increment in $\mathrm{mm}$ would decrease faster for similar volume growth (see Fig. 4; Bowman et al. 2013). This effect explains why the increase in model AUC between models that used sloRW and sloBAI was reported only for samples in which the alive observations arose from living trees.

Finally, A. alba trees exhibited higher inter-annual growth variability prior to death than surviving trees, and the magnitude of this relationship varied among sites, while the survival probability of $Q$. petraea and $N$. dombeyi was not correlated with growth variance. Interestingly, Suarez et al. (2004) found that dead N. dombeyi showed higher inter-annual growth variability than living ones. This contrasting result was due to the different metrics used to reveal growth variance, as they used $M S$ while the $S D$ of an AR1 model fitted to the detrended ring-width series was preferred here (see also Macalady and Bugmann 2014). This highlights the importance of carefully selecting the metrics, especially when estimating growth variance in rather short time

This article is protected by copyright. All rights reserved. 
series ( $p<50$ yrs). Other metrics may be used to characterize growth variance, such as the Gini index (Biondi and Qeadan 2008), the skewness in the ring-width distribution, or the number of pointer years (e.g. Das et al. 2007; see Appendix A). We encourage methodological studies devoted to this question (e.g. Bunn et al. 2013), but also the use of early warning detection methods (Dakos et al. 2012) that would reveal temporal trends in variance and autocorrelation in ring-width series, as both seem to increase before tree death (Appendix C; Camarero et al. 2015).

\section{TOWARDS A GENERAL METHODOLOGY}

Currently, it is not possible to carry out a meta-analysis of the growth-mortality relationships already published, as most of the authors followed different methodologies to derive them (Appendix A). The use of different (i) field and statistical sampling schemes, (ii) growth variables, and (iii) model performance metrics strongly influences model selection, and especially the time window that should be used to calculate each growth variable. Our study provides some recommendations based on general good modelling practice in order to obtain reliable results that can be compared among studies:

First of all, large sampling designs are important, i.e. hundreds of trees of various sizes growing at different sites should be sought (see Appendix D). Our study further highlights the necessity of (i) selecting a field and statistical sampling scheme that is consistent with the research question, and (ii) quantifying sampling-related biases. We suggest following a constant sampling approach to determine the time window that best discriminates growth patterns of living vs. dead trees, as changing the calibration dataset while increasing the maximum length of the time-window tested may bias this selection. Applying this method is all the more important since it can detect intraspecific shifts in growth-mortality relationships.

This article is protected by copyright. All rights reserved. 
Due to the exponential increase of computational power and of the robustness of statistical methods over the past years, novel approaches can now be used to derive growth-mortality relationships and optimize their performance. First, mixed-effect logistic models are strongly encouraged as they allow for quantifying the variability in growth-mortality relationships among sites, and can remove the potential impact of local disturbances on mortality that are independent of tree growth. Second, multivariate models should include different types of growth variables (growth level, trend, variance, temporal autocorrelation, etc.). Third, the time windows used to calculate the growth variables should be selected using appropriate optimisation procedures. Finally, we strongly recommend using AUC as the model performance metric for univariate models, as it depends less on sample size and on the ratio of alive/death observations than alternative metrics (e.g., AIC). However, in case of models with multiple inter-correlated variables, penalizing for extra parameters is important. In these cases we suggest evaluating models by considering multiple criteria, e.g, combining AUC with AIC to handle multicollinearity. Lastly, if the main goal of a study is to implement the mortality model in a Dynamic Vegetation Model (e.g., calibration with the sampling scheme $T$ and considering observed standscale mortality rates), binary metrics should be used to prevent any systematic over- or underestimation of mortality rates (see Bircher et al. 2015).

\section{Acknowledgments}

This study was conducted in the frame of the European COST Action STReESS (Studying Tree

Responses to extreme Events: a SynthesiS; FP1106) and benefited from constructive discussions within this research network. MC's postdoc was funded by the Swiss National Science

This article is protected by copyright. All rights reserved. 
Foundation (project number 140968). JJC thanks the support of projects CGL2011-26654 (Spanish Ministry of Economy and Competitiveness), 387/2011 and 1032S/2013 (OAPN, Spanish Ministry of Agriculture and Environment). IM was supported by the grants OTKAK68397 and OTKA-K101552 from the National Research Foundation of Hungary. ER's postdoc was funded by Research Foundation - Flanders (FWO, Belgium). JMV was funded by grants CGL2013-46808-R (MINECO) and 2014 SGR 453 (AGAUR). We would also like to thank Dario Martin-Benito for helpful discussions on tree-ring analyses, the editor and three anonymous reviewers for their suggestions that significantly improved the quality of the paper.

\section{References}

Allen, C. D., et al., 2010. Climate-induced forest mortality: a global overview of emerging risks. Forest Ecology and Management 259:660-684.

Allen, C. D., D. D. Breshears, and N. G. McDowell. 2015. On underestimation of global vulnerability to tree mortality and forest die-off from hotter drought in the Anthropocene. Ecosphere 6:art129.

Austin, P. C. 2007. A comparison of regression trees, logistic regression, generalized additive models, and multivariate adaptive regression splines for predicting AMI mortality. Statistics in Medicine 26:2937-2957.

Bates, D., M. Maechler, B. Bolker, and S. Walker. 2015. lme4: Linear mixed-effects models using Eigen and S4. R package version 1.1-8, http://CRAN.R-project.org/package=lme4

Bennett, A. C., N. G. McDowell, C. D. Allen, and K. J. Anderson-Teixeira. 2015. Larger trees suffer most during drought in forests worldwide. Nature Plants 1:15139.

This article is protected by copyright. All rights reserved. 
Bigler, C., and H. Bugmann. 2004. Predicting the time of tree death using dendrochronological data. Ecological Applications 14:902-914.

Bigler, C., D. G. Gavin, C. Gunning, and T. T. Veblen. 2007. Drought induces lagged tree mortality in a subalpine forest in the Rocky Mountains. Oikos 116:1983-1994.

Bigler, C., J. Gričar, H. Bugmann, and K. Čufar. 2004. Growth patterns as indicators of impending tree death in silver fir. Forest Ecology and Management 199:183-190.

Bigler, C., and A. Rigling. 2013. Prediction and accuracy of tree-ring-based death dates of mountain pines in the Swiss National Park. Trees 27:1703-1712.

Biondi, F., and F. Qeadan. 2008. Inequality in paleorecords. Ecology 89:1056-1067.

Bircher, N., M. Cailleret, and H. Bugmann. 2015. The agony of choice: different empirical models lead to sharply different future forest dynamics. Ecological Applications 25:13031318.

Bowman, D. M. J. S., R. J. W. Brienen, E. Gloor, O. L. Phillips, and L. D. Prior. 2013. Detecting trends in tree growth: not so simple. Trends in Plant Science 18:11-17.

Bravo-Oviedo, A., H. Sterba, M. del Río, and F. Bravo. 2006 Competition-induced mortality for Mediterranean Pinus pinaster Ait. and P. sylvestris L. Forest Ecology and Management 222:88-98.

Bunn, A. G., E. Jansma, M. Korpela, R. D. Westfall, and J. Baldwin. 2013 Using simulations and data to evaluate mean sensitivity as a useful statistic in dendrochronology. Dendrochronologia $31: 250-254$.

Cailleret, M., M. Nourtier, A. Amm, M. Durand-Gillmann, and H. Davi. 2014 Drought-induced decline and mortality of silver fir differ among three sites in Southern France. Annals of Forest Science 71:643-657.

This article is protected by copyright. All rights reserved. 
Camarero, J. J., A. Gazol, G. Sangüesa-Barreda, J. Oliva, and S. M. Vicente-Serrano. 2015. To die or not to die: early warnings of tree dieback in response to a severe drought. Journal of Ecology 103:44-57.

Carpenter, S. R., W. A. Brock, J. J. Cole, and M. L. Pace. 2014. A new approach for rapid detection of nearby thresholds in ecosystem time series. Oikos 123:290-297.

Clifford, M. J., P. D. Royer, N. S. Cobb, and D. D. Breshears. 2013. Precipitation thresholds and drought-induced tree die-off: insights from patterns of Pinus edulis mortality along an environmental stress gradient. New Phytologist 200:413-421.

Collins, M., et al. 2013. Long-term Climate Change: Projections, Commitments and Irreversibility. In T. F. Stocker, et al., editors. Climate Change 2013: The Physical Science Basis. Contribution of Working Group I to the Fifth Assessment Report of the Intergovernmental Panel on Climate Change. Cambridge University Press, Cambridge, United Kingdom and New York, NY, USA.

Cook, E. R., and K. Peters. 1997. Calculating unbiased tree-ring indices for the study of climatic and environmental change. Holocene 7: 361-370.

Dakos, V., S.R. Carpenter, W.A. Brock, A.M. Ellison, V. Guttal, A.R. Ives, et al. 2012. Methods for Detecting Early Warnings of Critical Transitions in Time Series Illustrated Using Simulated Ecological Data. PLoS ONE 7(7): e41010.

Das, A. J., J. J. Battles, N. L. Stephenson, and P. J. van Mantgem. 2007. The relationship between tree growth patterns and likelihood of mortality: a study of two tree species in the Sierra Nevada. Canadian Journal of Forest Research 37:580-597.

Das, A.J., J.J. Battles, P. J. van Mantgem, and N. L. Stephenson. 2008. Spatial elements of mortality risk in old-growth forests. Ecology, 89:1744-1756.

This article is protected by copyright. All rights reserved. 
Das, A. J., and N. L. Stephenson. 2015. Improving estimates of tree mortality probability using potential growth rate. Canadian Journal of Forest Research 425:920-928.

Das, A. J., N. L. Stephenson, A. Flint, T. Das, and P. van Mantgem. 2013. Climatic correlates of tree mortality in water- and energy-limited forests. PlosOne, 8(7):e69917.

Dorman, M., T. Svoray, A. Perevolotsky, Y. Moshe, and D. Sarris. 2015. What determines tree mortality in dry environments? A multi-perspective approach. Ecological Application 25:1054-1071.

Esper, J., E. R. Cook, P. J. Krusic, K. Peters, and F. H. Schweingruber. 2003. Tests of the RCS method for preserving low-frequency variations in long tree-ring chronologies. Tree Ring Research 59:81-98.

Ferrenberg, S., J. N. Kane, and J. B. Mitton. 2014. Resin duct characteristics associated with tree resistance to bark beetles across lodgepole and limber pines. Oecologia 174:1283-1292.

Fielding, A. H., and J. F. Bell. 1997. A review of methods for the assessment of prediction errors in conservation presence/absence models. Environmental Conservation 24:38-49.

Friend, A. D., et al. 2014. Carbon residence time dominates uncertainty in terrestrial vegetation responses to future climate and atmospheric $\mathrm{CO} 2$. Proceedings of the National Academy of Sciences of the United States of America 111:3280-3285.

Gillner, S., N. Rüger, A. Roloff, and U. Berger. 2013. Low relative growth rates predict future mortality of common beech (Fagus sylvatica L.). Forest Ecology and Management 302:372378.

Hadfield, J. D. 2010. MCMC methods for multi-response generalized linear mixed models: the MCMCglmm R package. Journal of Statistical Software 33:1-22.

Hartmann, H., C. Messier, and M. Beaudet. 2007. Improving tree mortality models by accounting for environemental influences. Canadian Journal of Forest Research 37:2106-2114.

This article is protected by copyright. All rights reserved. 
Hasenauer, H., D. Merkl, and M. Weingartner. 2001. Estimating tree mortality of Norway spruce stands with neural networks. Advances in Environmental Research 5:401-414.

Heinze, G., M. Ploner, D. Dunkler, and H. Southworth. 2013. Logistf: Firth's bias reduced logistic regression. $\mathrm{R}$ package version 1.21. http://cemsiis.meduniwien.ac.at/en/kb/scienceresearch/software/statistical-software/fllogistf/

Heres, A.M., Camarero, J.J., López, B.C., Martínez-Vilalta, J. 2014. Declining hydraulic performances and low carbon investments in tree rings predate Scots pine drought-induced mortality. Trees 28:1737-1750.

Holzwarth, F., A. Kahl, J. Bauhus, and C. Wirth. 2013. Many ways to die - partitioning tree mortality dynamics in a near-natural mixed deciduous forest. Journal of Ecology 101:220-230.

Kane, J. M., and T. E. Kolb. 2010. Importance of resin ducts in reducing ponderosa pine mortality from bark beetle attack. Oecologia 164:601-609.

Kane, J. M., and T. E. Kolb. 2014. Short- and long-term growth characteristics associated with tree mortality in southwestern mixed-conifer forests. Canadian Journal of Forest Research 44:1227-1235.

Lawson, C. R., J. A. Hodgson, R. J. Wilson, and S. A. Richards. 2014. Prevalence, thresholds and the performance of presence-absence models. Methods in Ecology and Evolution 5:54-64.

Lempereur, M., N. K. Martin-StPaul, C. Damesin, R. Joffre, J. M. Ourcival, A. Rocheteau, and S. Rambal. 2015. Growth duration is a better predictor of stem increment than carbon supply in a Mediterranean oak forest: implications for assessing forest productivity under climate change. New Phytologist 207:579-590.

Linares, J. C., and J. J. Camarero. 2012. Growth patterns and sensitivity to climate predict silver fir decline in the Spanish Pyrenees. European Journal of Forest Research 131:1001-1012.

This article is protected by copyright. All rights reserved. 
Lombardi, F., P. Cherubini, B. Lasserre, R. Tognetti, and M. Marchetti. 2008. Tree rings used to assess time since death of deadwood of different decay classes in beech and silver fir forests in the central Apennines (Molise, Italy). Canadian Journal of Forest Research 38:821-833.

Macalady, A. K., and H. Bugmann. 2014. Growth-mortality relationships in piñon pine (Pinus edulis) during severe droughts of the past century: shifting processes in space in time. PlosOne 9(5): e92770. doi:10.1371/journal.pone.0092770

Martín-Benito, D., P. Cherubini, M. del Río, and I. Cañellas. 2008. Growth response to climate and drought in Pinus nigra Arn. trees of different crown classes. Trees 22:363-373.

McDowell, N. G., et al. 2013. Evaluating theories of drought-induced vegetation mortality using a multi-model experiment framework. New Phytologist 200:304-321.

Mérian, P., J. C. Pierrat, and F. Lebourgeois. 2013. Effect of sampling effort on the regional chronology statistics and climate-growth relationships estimation. Dendrochronologia 31:5867.

Mullen, K. M., D. Ardia, D. L. Gil, D. Windover, and J. Cline. 2011. DEoptim: An R Package for Global Optimization by Differential Evolution. Journal of Statistical Software 40(6):1-26.

Nerhbass-Ahles, C., F. Babst, S. Klesse, M. Nötzli, O. Bouriaud, R. Neukom, M. Dobbertin, and D. Frank. 2014. The influence of sampling design on tree-ring-based quantification of forest growth. Global Change Biology 20:2867-2885.

Palacio, S., G. Hoch, A. Sala, C. Körner, and P. Millard. 2014. Does carbon storage limit tree growth? New Phytologist 201:1096-1100.

Pedersen, B. S. 1998. The role of stress in the mortality of Midwestern oaks as indicated by growth prior to death. Ecology 79:79-93.

Puri, E., G. Hoch, and C. Körner. 2015. Defoliation reduces growth but not carbon reserves in Mediterranean Pinus pinaster trees. Trees 29:1187-1996.

This article is protected by copyright. All rights reserved. 
Ryan, M. G., N. Phillips, and B. J. Bond. 2006. The hydraulic limitation revisited. Plant Cell and Environment 29:367-381.

Scheffer, M. et al. 2012. Anticipating Critical Transitions. Science 338:344-348.

Schulman, E. 1958. Bristlecone pine, oldest known living thing. National Geographic 113:355372

Sing, T., O. Sander, N. Beerenwinkel, and T. Lengauer. 2013. Package 'ROCR': Visualizing the performance of scoring classifiers. http://rocr.bioinf.mpi-sb-mpg.de

Storn, R., and K. Price, K. 1997. Differential evolution-a simple and efficient heuristic for global optimization over continuous spaces. Journal of global optimization 11:341-359.

Suarez, M. L., L. Ghermandi, and T. Kitzberger. 2004. Factors predisposing episodic droughtinduced tree mortality in Nothofagus - site, climatic sensitivity and growth trends. Journal of Ecology 92:954-966.

Swets, J. A. 1988. Measuring the accuracy of diagnostic systems. Science 240:1285-1293.

Tague, C. L., N. G. Mc Dowell, and C. D. Allen. 2013. An Integrated Model of Environmental Effects on Growth, Carbohydrate Balance, and Mortality of Pinus ponderosa Forests in the Southern Rocky Mountains. PlosOne 8(11): e80286. doi:10.1371/journal.pone.0080286

Valladares. F., and Ü. Niinemets. 2008. Shade Tolerance, a Key Plant Feature of Complex Nature and Consequences. Annual Review of Ecology, Systematics and Evolution 39:235-257.

van Mantgem, P.J., et al., 2009. Widespread increase of tree mortality rates in the western United States. Science 323:521-524.

Vilà-Cabrera, A., J. Martínez-Vilalta, L. Galiano, and J. Retana. 2013. Patterns of forest decline and regeneration across Scots pine populations. Ecosystems 16:323-335.

This article is protected by copyright. All rights reserved. 
Wunder, J., B. Brzeziecki, H. Żybura, B. Reineking, C. Bigler, and H. Bugmann. 2008. Growthmortality relationships as indicators of life-history strategies: a comparison of nine tree species in unmanaged European forests. Oikos 117:815-828.

Wyckoff, P. H., and J. S. Clark. 2000. Predicting tree mortality from diameter growth: a comparison of maximum likelihood and Bayesian approaches. Canadian Journal of Forest Research 30:156-167.

Wyckoff, P. H., and J. S. Clark. 2002. The relationship between growth and mortality for seven co-occurring tree species in the southern Appalachian Mountains. Journal of Ecology 90:604615.

\section{Supplementary Materials}

Appendix A: Literature review of several tree-ring based mortality models.

Appendix B: Details on the field sampling.

Appendix C: Effect of the status of the trees used to sample the 'alive' observations.

Appendix D: Effect of sample size on the comparison of the best-fitting $p$ of univariate models determined using the classical and the constant sampling approaches, and on the performance of multivariate models.

Appendix E: Effect of the random selection of the 'alive' observations.

Appendix F: Effect of sample characteristics on model AIC and AUC.

Appendix G: Determination of the best ARMA model.

Appendix H: Best-fitting $p$ of univariate models with growth level and trend variables considering all sampling schemes.

Appendix I: Performance of log-transformed univariate models.

This article is protected by copyright. All rights reserved. 
Appendix J: Correlation coefficients between growth variables.

Appendix K: Effect size of the fixed effects of multivariate models.

Table 1: Main characteristics of the datasets used to assess growth-mortality relationships. The ranges in DBH and cambial age (defined at coring height; $1.3 \mathrm{~m}$ ) are $95 \%$ confidence intervals.

\begin{tabular}{|c|c|c|c|c|c|c|c|c|}
\hline Species & Sites & Article & $\begin{array}{l}\text { Formati } \\
\text { on year } \\
\text { of last } \\
\text { ring }\end{array}$ & $\begin{array}{l}\mathrm{Nb} \\
\text { dead } \\
\text { trees }\end{array}$ & $\begin{array}{l}\mathrm{Nb} \\
\text { livin } \\
\mathrm{g} \\
\text { trees }\end{array}$ & $\begin{array}{l}\mathrm{DBH} \\
\text { range } \\
(\mathrm{cm})\end{array}$ & $\begin{array}{l}\text { Cambi } \\
\text { al age } \\
\text { range }\end{array}$ & $\begin{array}{l}\text { Period of } \\
\text { mortality }\end{array}$ \\
\hline \multirow{3}{*}{$\begin{array}{l}\text { Abies } \\
\text { alba }\end{array}$} & $\begin{array}{l}\text { Bistra } \\
\text { Ravnik }\end{array}$ & Bigler et al. 2004 & 2001 & $\begin{array}{l}2 \\
16\end{array}$ & $\begin{array}{l}17 \\
16\end{array}$ & $\begin{array}{l}38-59 \\
27-57\end{array}$ & $\begin{array}{l}100- \\
167 \\
73-189\end{array}$ & 1988-2001 \\
\hline & $\begin{array}{l}\text { Ventoux_Dvx3 } \\
\text { Vesubie3 } \\
\text { Vesubie6 } \\
\text { Ventoux_TC }\end{array}$ & $\begin{array}{l}\text { Cailleret et al. } \\
2014\end{array}$ & 2009 & $\begin{array}{l}8 \\
8 \\
11 \\
10 \\
9 \\
1\end{array}$ & $\begin{array}{l}19 \\
12 \\
19 \\
15 \\
17 \\
12\end{array}$ & $\begin{array}{l}15-38 \\
18-40 \\
19-45 \\
16-31 \\
19-56 \\
31-76\end{array}$ & $\begin{array}{l}66-166 \\
53-95 \\
51-87 \\
39-113 \\
81-112 \\
135- \\
184 \\
46-168\end{array}$ & 1998-2008 \\
\hline & $\begin{array}{l}\text { Paco_Ezpela_H } \\
\text { igh }\end{array}$ & $\begin{array}{l}\text { Linares and } \\
\text { Camarero } 2012\end{array}$ & 2000 & 3 & $\begin{array}{l}7 \\
7\end{array}$ & $\begin{array}{l}28-47 \\
38-51\end{array}$ & $\begin{array}{l}73-116 \\
92-154\end{array}$ & 1996-2000 \\
\hline
\end{tabular}

This article is protected by copyright. All rights reserved. 


\begin{tabular}{|c|c|c|c|c|c|c|c|c|}
\hline & $\begin{array}{l}\text { Paco_Ezpela_L } \\
\text { ow } \\
\text { Lopet }\end{array}$ & & & 2 & 7 & $26-51$ & $79-128$ & \\
\hline & Canalicchio & $\begin{array}{l}\text { Lombardi et al. } \\
2008\end{array}$ & 2005 & 51 & 15 & $10-71$ & $46-163$ & 1955-2002 \\
\hline $\begin{array}{l}\text { Nothofag } \\
\text { us } \\
\text { dombeyi }\end{array}$ & Cerro_Otto & Suarez et al. 2004 & 1997 & 43 & 43 & $11-57$ & $21-124$ & 1998 \\
\hline $\begin{array}{l}\text { Quercus } \\
\text { petraea }\end{array}$ & Sikfokut & Meszaros unpub & 2012 & 25 & 194 & $\begin{array}{l}22- \\
41 \dagger\end{array}$ & $55-104$ & 1953-2009 \\
\hline
\end{tabular}

$\uparrow$ The DBH of dead Quercus petraea trees was not measured

This article is protected by copyright. All rights reserved. 
Table 2: Range of AUC of the single-variable models obtained at best-fitting $p$ (in brackets) with the constant sampling approach for each species, statistical sampling scheme, and growth variable studied. Boldface types indicate that the effect of growth $h_{i, t, p}$ on $Y_{i, t}$ was significant (pvalue $<0.05)$ for the model calibrated at best-fitting $p$ with all the possible samples. $\dagger$ means that the effect of the growth variable differed among sites (best model includes the random effect of growth grouped by site); + means significant effect of the intercept grouped by site nested in year; (+) and (-) respectively reveal a positive and negative relationship between each growth variable with survival probability, and $\S$ indicates that the sign of the relationship is different from the general pattern.

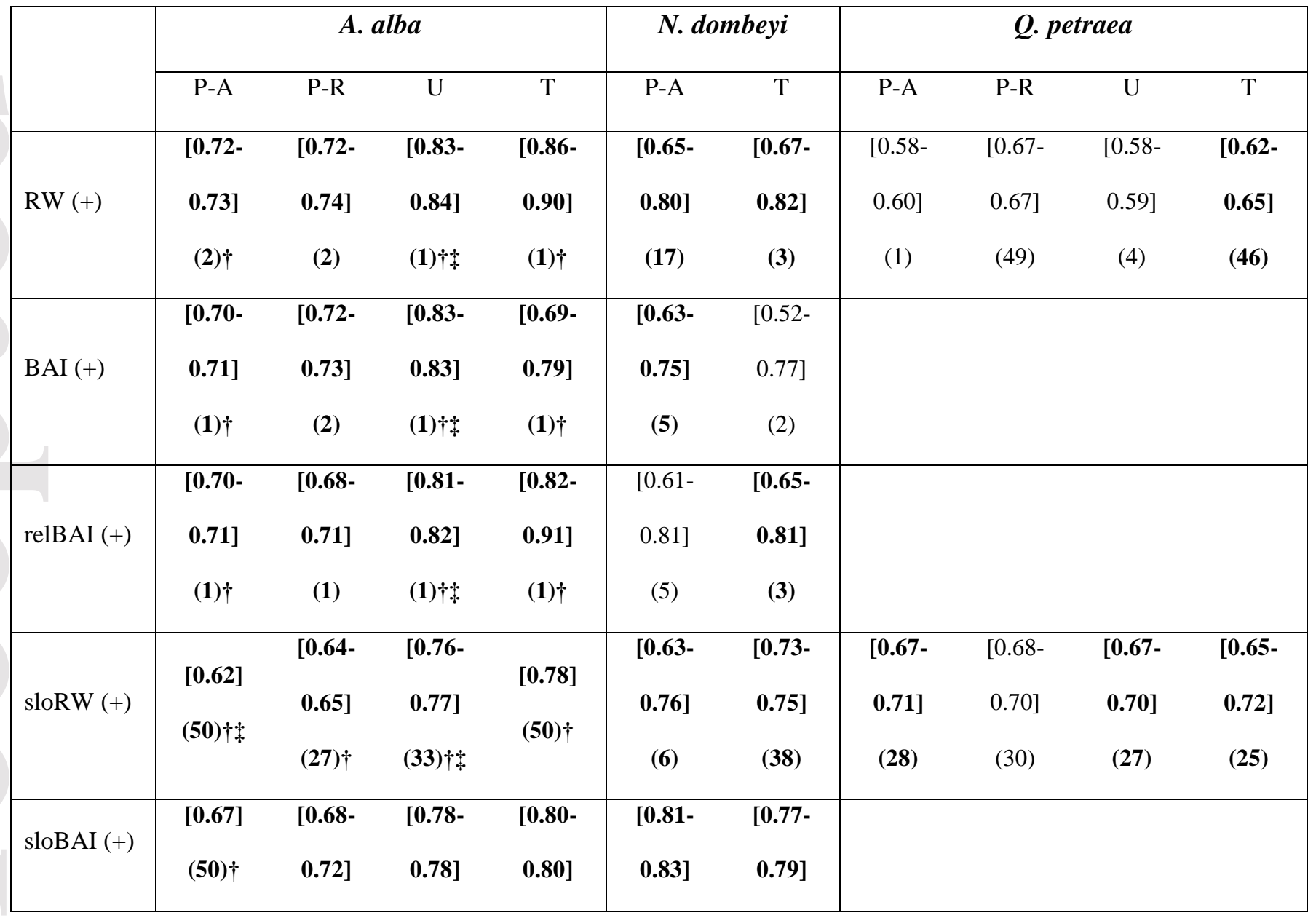

This article is protected by copyright. All rights reserved. 


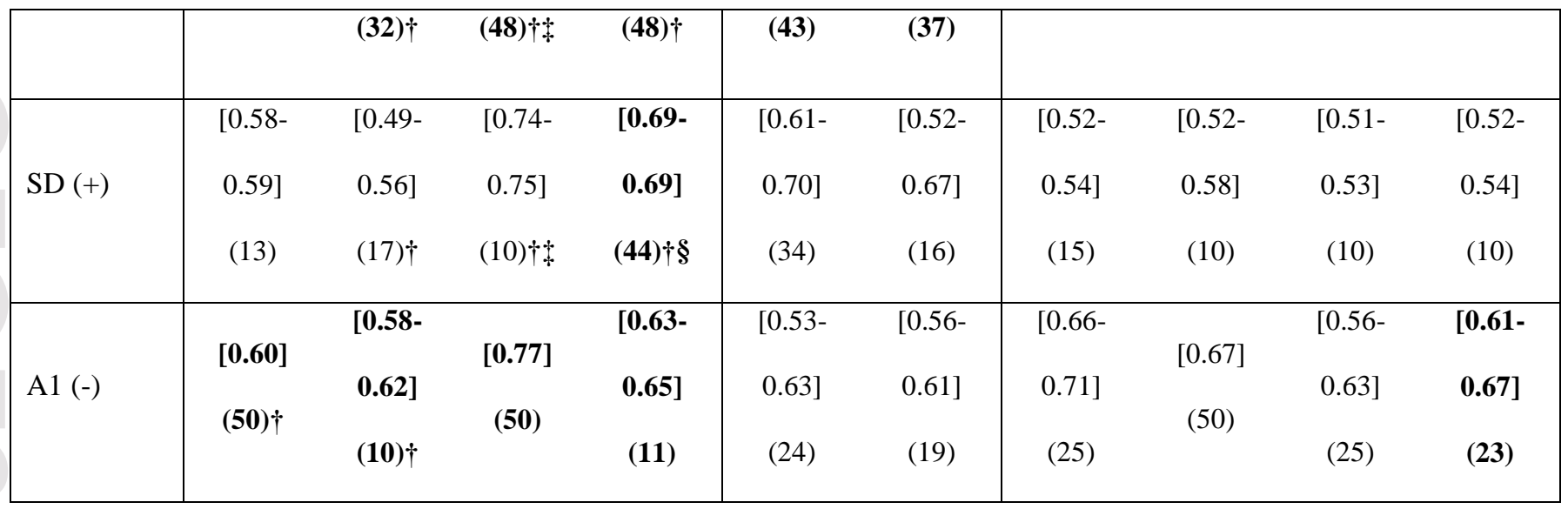

Table 3: Time windows ( $p$; number of years preceding the 'dead' or 'live' observation) used to calculate the growth variables included in the best multivariate mortality model, including: mean ring width (RW), the temporal trend of RW (sloRW), and the standard deviation (SD) and lag-1 autocorrelation (A1) of the RW time series. Models were calibrated using different $p_{\max }$ and statistical samplings of 'dead' and 'live' observations. We used the total sample, i.e. all the rings (T), or focused only on those years when mortality occurred. In the latter case, we considered all 'live' observations (U), or generated dead/live pairs (trees of same age: P-A, or randomly: P-R). (+) and (-) respectively significant positive and negative effects of each growth variable on tree survival probability (*: p-value $<0.05 ; * *$ : p-value $<0.01 ; * * *$ : p-value $<0.001) . \dagger$ and $\uparrow$ indicate significant random effects of the growth variables grouped by site and of the intercept grouped by site nested in year on survival probability, respectively.

\begin{tabular}{|c|c|c|c|c|c|c|c|c|c|c|}
\hline \multirow[b]{2}{*}{$\begin{array}{l}p_{\max }=2 \\
0\end{array}$} & \multicolumn{4}{|c|}{ Abies alba } & \multicolumn{2}{|c|}{$\begin{array}{c}\text { Nothofagus } \\
\text { dombeyi }\end{array}$} & \multicolumn{4}{|c|}{ Quercus petraea } \\
\hline & P-A & P-R & $\mathbf{U}$ & $\mathbf{T}$ & P-A & $\mathbf{T}$ & P-A & P-R & $\mathbf{U}$ & $\mathbf{T}$ \\
\hline \multirow{2}{*}{ RW } & 2 & 2 & 1 & 1 & 18 & 3 & 20 & 1 & 1 & 1 \\
\hline & $(+) * * *$ & $(+)^{* * * *}$ & $(+)^{* * *}$ & $(+)^{* * *}$ & $(+)^{* *}$ & $(+) * * *$ & & & & $(+)^{*}$ \\
\hline
\end{tabular}

This article is protected by copyright. All rights reserved. 


\begin{tabular}{|c|c|c|c|c|c|c|c|c|c|c|}
\hline sloRW & 4 & 20 & 5 & 16 & $\begin{array}{c}3 \\
(-)^{*}\end{array}$ & $\begin{array}{c}7 \\
(+)^{* * *}\end{array}$ & $\begin{array}{c}5 \\
(+)^{*}\end{array}$ & 20 & 13 & 6 \\
\hline SD & 10 & 18 & 17 & $\begin{array}{c}18 \\
(-)^{* *}\end{array}$ & 17 & 20 & 12 & 16 & 15 & 10 \\
\hline A1 & 19 & $\begin{array}{c}11 \\
(-)^{*}\end{array}$ & 11 & $\begin{array}{c}10 \\
(-)^{* * *}\end{array}$ & 13 & $\begin{array}{c}11 \\
(-)^{*}\end{array}$ & 10 & 19 & 13 & 20 \\
\hline AUC & $\begin{array}{c}0.742 \\
\dagger t\end{array}$ & $\begin{array}{c}0.799 \\
\dagger\end{array}$ & $\begin{array}{c}0.850 \\
\dagger+\end{array}$ & $\begin{array}{c}0.916 \\
\dagger\end{array}$ & 0.751 & 0.781 & 0.731 & 0.688 & 0.673 & 0.675 \\
\hline $\begin{array}{l}p_{\max }=3 \\
5\end{array}$ & P-A & P-R & $\mathbf{U}$ & $\mathbf{T}$ & P-A & $\mathbf{T}$ & P-A & P-R & $\mathbf{U}$ & $\mathbf{T}$ \\
\hline RW & $\begin{array}{c}3 \\
(+)^{* * *}\end{array}$ & $\begin{array}{c}2 \\
(+)^{* * *}\end{array}$ & $\begin{array}{c}2 \\
(+)^{* * *}\end{array}$ & $\begin{array}{c}3 \\
(+)^{* * *}\end{array}$ & $\begin{array}{c}17 \\
(+)^{* *}\end{array}$ & $\begin{array}{c}3 \\
(+)^{* * *}\end{array}$ & 13 & 13 & 1 & 4 \\
\hline sloRW & $\begin{array}{c}4 \\
(+)^{*}\end{array}$ & 24 & $\begin{array}{c}31 \\
(+)^{* * *}\end{array}$ & $\begin{array}{c}3 \\
(+)^{* * *}\end{array}$ & 12 & $\begin{array}{c}35 \\
(+)^{*}\end{array}$ & $\begin{array}{c}5 \\
(+)^{*}\end{array}$ & $\begin{array}{c}34 \\
(+)^{*}\end{array}$ & $\begin{array}{c}27 \\
(+)^{* *}\end{array}$ & $\begin{array}{c}28 \\
(+)^{*}\end{array}$ \\
\hline SD & 24 & $\begin{array}{l}25 \\
(-)^{*}\end{array}$ & 35 & $\begin{array}{c}17 \\
(-)^{* * *}\end{array}$ & 29 & 12 & 22 & 10 & 11 & 10 \\
\hline A1 & 22 & $\begin{array}{c}10 \\
(-)^{*}\end{array}$ & 35 & $\begin{array}{c}12 \\
(-)^{* * *}\end{array}$ & 35 & $\begin{array}{c}11 \\
(-)^{* *}\end{array}$ & $\begin{array}{c}24 \\
(-)^{*}\end{array}$ & 29 & 35 & 23 \\
\hline AUC & $\begin{array}{c}0.737 \\
+t\end{array}$ & $\begin{array}{c}0.808 \\
\dagger+\end{array}$ & $\begin{array}{c}0.854 \\
\dagger+\end{array}$ & $\begin{array}{c}0.911 \\
\dagger\end{array}$ & 0.849 & 0.856 & 0.754 & 0.762 & 0.701 & 0.700 \\
\hline $\begin{array}{l}p_{\max }=5 \\
0\end{array}$ & P-A & P-R & $\mathbf{U}$ & $\mathbf{T}$ & P-A & $\mathbf{T}$ & P-A & P-R & $\mathbf{U}$ & $\mathbf{T}$ \\
\hline RW & $\begin{array}{c}6 \\
(+)^{* * *}\end{array}$ & $\begin{array}{c}42 \\
(+)^{* * *}\end{array}$ & $\begin{array}{c}2 \\
(+)^{* * *}\end{array}$ & $\begin{array}{c}3 \\
(+)^{* * *}\end{array}$ & $\begin{array}{c}10 \\
(+)^{* *}\end{array}$ & $\begin{array}{c}12 \\
(+)^{* * *}\end{array}$ & 7 & 50 & 5 & 50 \\
\hline sloRW & $\begin{array}{c}4 \\
(+)^{* *}\end{array}$ & $\begin{array}{c}25 \\
(+)^{* * *}\end{array}$ & $\begin{array}{c}31 \\
(+)^{* * *}\end{array}$ & $\begin{array}{c}4 \\
(+)^{* * *}\end{array}$ & $\begin{array}{c}41 \\
(+)^{*}\end{array}$ & $\begin{array}{c}7 \\
(+)^{* *}\end{array}$ & $\begin{array}{c}34 \\
(+)^{*}\end{array}$ & 9 & $\begin{array}{c}27 \\
(+)^{* *}\end{array}$ & $\begin{array}{c}28 \\
(+)^{*}\end{array}$ \\
\hline SD & 24 & 23 & 43 & 23 & 33 & 31 & 41 & 26 & 17 & 28 \\
\hline
\end{tabular}

This article is protected by copyright. All rights reserved. 


\begin{tabular}{|c|c|c|c|c|c|c|c|c|c|c|}
\hline & & & $(-)^{* *}$ & $(-)^{*}$ & \multirow{3}{*}{$\begin{array}{c}36 \\
(+)^{*}\end{array}$} & \multirow{3}{*}{13} & \multirow{3}{*}{11} & \multirow{3}{*}{50} & \multirow{3}{*}{11} & \multirow{3}{*}{23} \\
\hline \multirow{2}{*}{ A1 } & \multirow[t]{2}{*}{41} & 10 & & 12 & & & & & & \\
\hline & & $(-)^{*}$ & 43 & $(+)^{* * * *}$ & & & & & & \\
\hline \multirow{2}{*}{ AUC } & 0.743 & 0.794 & 0.853 & 0.903 & \multirow[t]{2}{*}{0.926} & \multirow[t]{2}{*}{0.868} & \multirow[t]{2}{*}{0.798} & \multirow[t]{2}{*}{0.798} & \multirow[t]{2}{*}{0.719} & \multirow[t]{2}{*}{0.750} \\
\hline & $\dagger t$ & $\dagger t$ & $\dagger t$ & $\dagger$ & & & & & & \\
\hline
\end{tabular}

Figure legends

\section{Figure 1:}

Top-Left: Ring-width (black) and Basal Area Increment (grey) chronologies of tree BIS999 (Abies alba; site Bistra) and the growth variables used as predictors of tree survival probability. Variables that reflect growth level (mean $R W$, mean $B A I$ ), growth trend (sloRW, sloBAI; slope of the linear regression represented by the dotted line), and the variance (SD) and lag-1 autocorrelation $(A 1)$ in the ring-width series are shown for a time window $(p)$ of 25 years (dark grey polygon). The grey polygon reveals the different time windows tested, from 1 to 50 years. Top-Right and Bottom: Change over time of the median $R W$ (dark colors) and median BAI (light colors) of living (solid line) and dead trees (dashed line) for A. alba (blue), Q. petraea (red), and N. dombeyi (green).

Figure 2: Top: Change in the number of pairs used (crosses) to calibrate the logistic model when increasing the number of rings $p$ used to calculate $R W_{i, t, p}$ for $A$. alba (Left; blue; sampling $P-A$ ), Q. petraea (Centre; red; sampling $P-A$ ) and $N$. dombeyi (Right; green; sampling $P-A$ ). Change in the AUC value of logistic models that use $R W_{i, t, p}$ (Middle) and $s l o R W_{i, t, p}($ Bottom) as single predictor of tree mortality according to the length of the time window $(p)$ used to calculate this

This article is protected by copyright. All rights reserved. 
growth variable. The coloured curves reflect the change in AUC using the classical approach. The different black and grey curves reflect the change in AUC with different samples whose size is constant over $p$ (grey lines indicate that the growth-mortality relationship was not significant at this $p$ ). At each $p$, we calculated the proportion of these samples for which AUC is maximized at this specific $p$ and reported this value in the histograms shown in the bottom-most panels.

Figure 3: Change in the frequency of $n$ that maximizes AUC of models that used $R W_{i, t, p}(T o p)$ and $s l o R W_{i, t, p}$ (Bottom) to predict survival probability of A. alba (blue), Q. petraea (red) and $N$. dombeyi (green) according to the statistical sampling scheme used. The larger is the coloured rectangle, the higher is the number of samples for which maximum AUC is obtained at this $p$. Transparent rectangles with black borders reveal the best-fitting $p$ obtained with the classical approach.

Figure 4: Change over time of the median RW (Top) and median BAI (Bottom) of living (solid line) and dead (dashed line) N. dombeyi for both young (<=30 years old; black; 13 pairs) and old trees (grey; 30 pairs) included in the sampling P-A.

This article is protected by copyright. All rights reserved. 

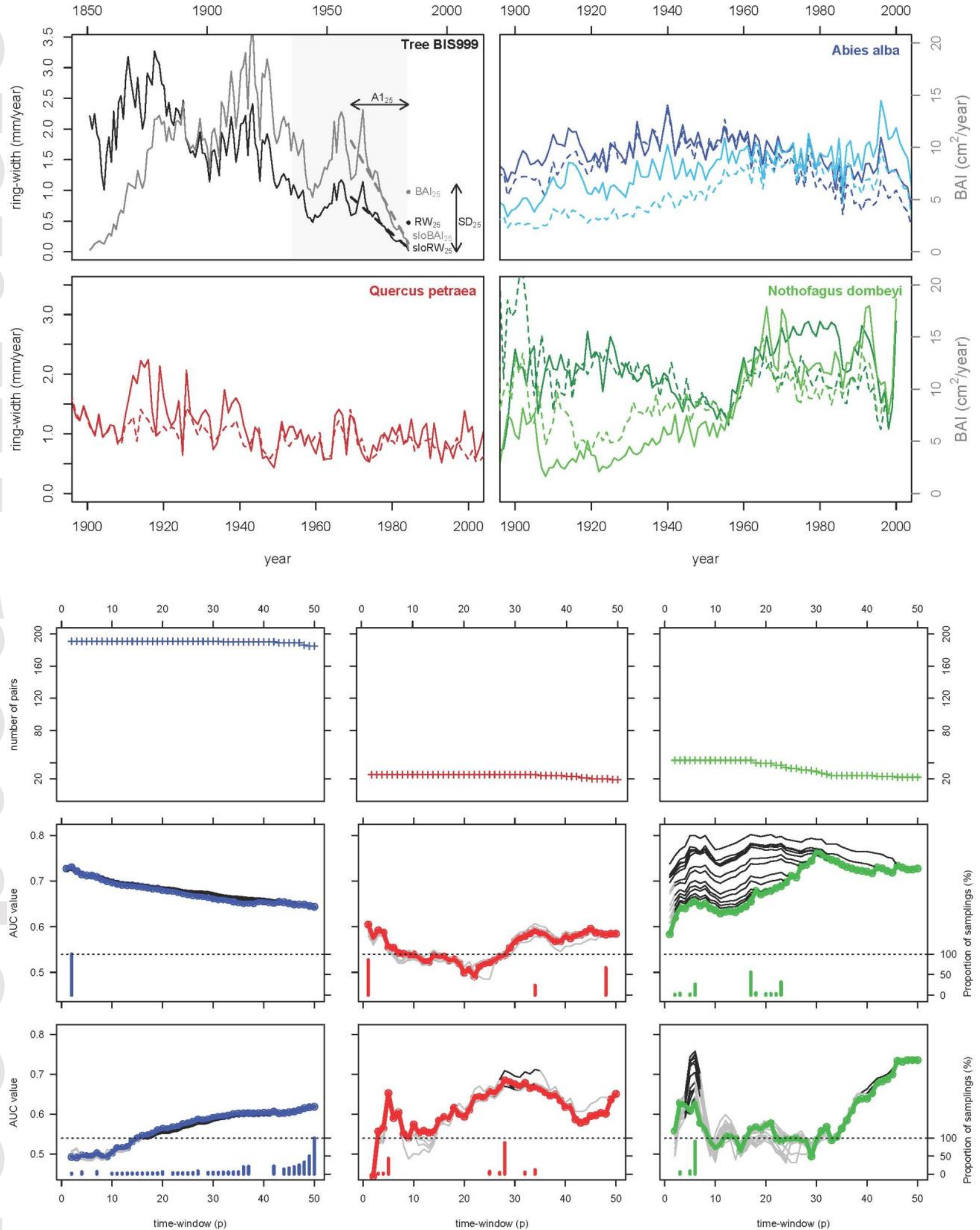

This article is protected by copyright. All rights reserved. 

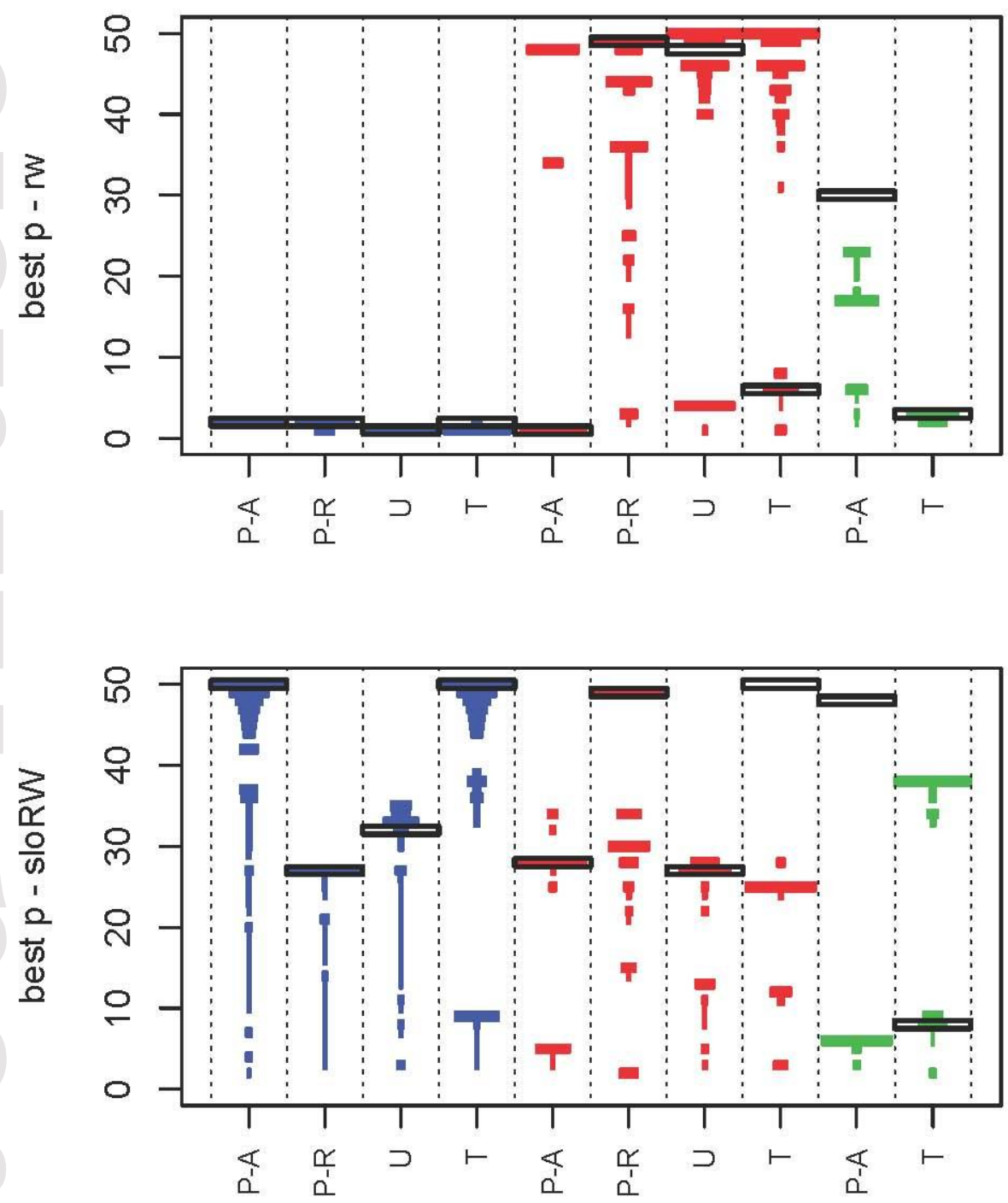

This article is protected by copyright. All rights reserved. 

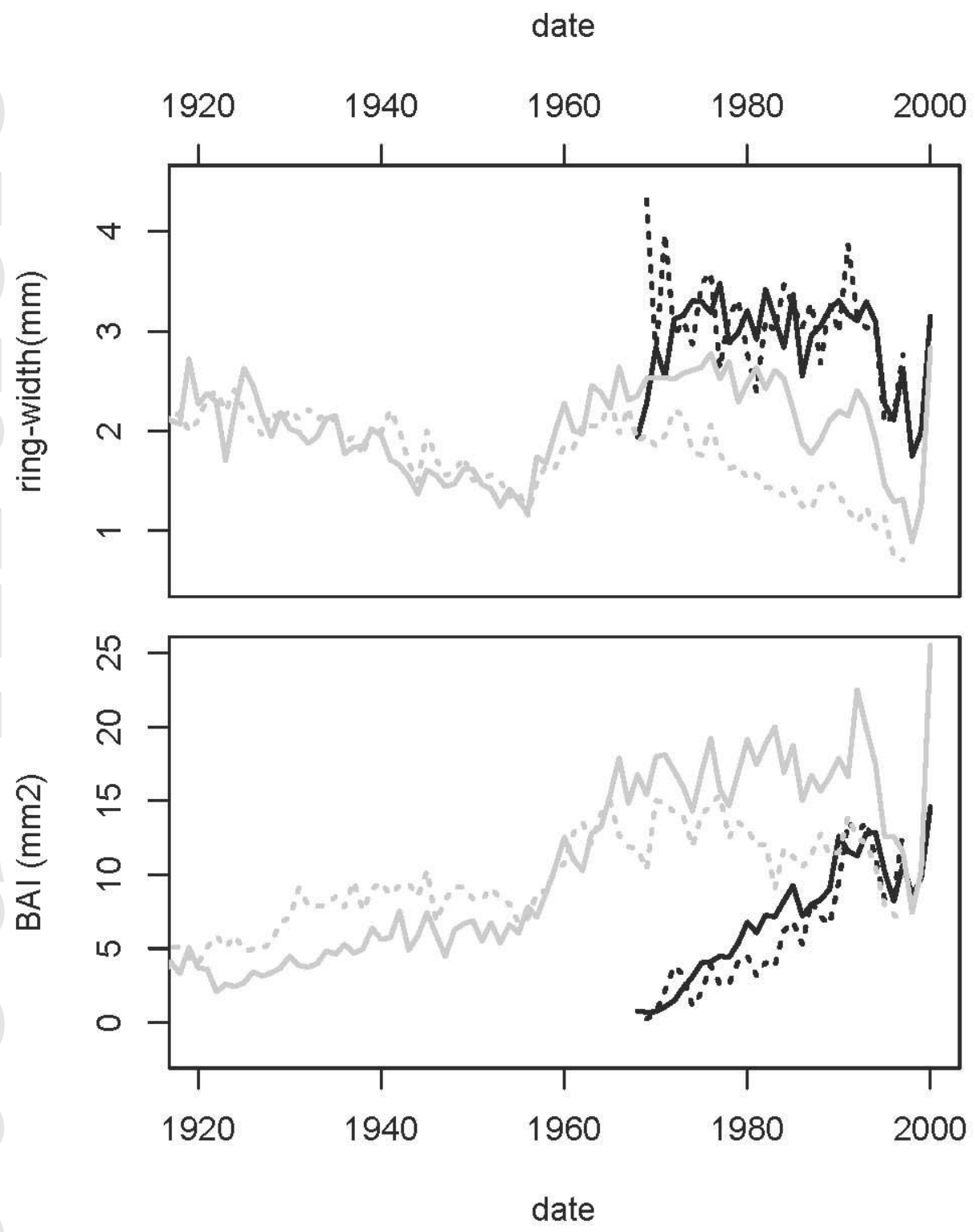

This article is protected by copyright. All rights reserved. 